\author{
Атауллина Рузалия Ринатовна \\ Магистрант кафедры бухгалтерского учета и налогообложения \\ Российский экономический университет имени Г.В.Плеханова, \\ Российская Федерация, г. Москва, 117997, Стремянный пер., 36 \\ E-mail: ruzaliaa04@gmail.com
}

\title{
РАЗВИТИЕ ЯЗЫКОВ ПРОГРАММИРОВАНИЯ И ЭЛЕКТРОННЫХ ФОРМАТОВ ОБМЕНА ДЕЛОВЫМИ ДАННЫМИ В БИЗНЕС - СРЕДЕ
}

\begin{abstract}
Аннотация. В статье проведено исследование электронных форматов обмена деловыми данными в бизнес-среде. Особое внимание уделено терминологическому пониманию «языки программирования», их развития и классификации. Определено, что развитие языков программирования во многом зависит от эволюции компьютерной техники. Классификация языков программирования может быть детализирована по функциональному признаку или парадигме программирования. По результатам проведенного исследования представлено авторское мнение о тенденциях развития основных электронных форматах обмена деловыми данными, которые применяются в бизнес-среде. Статья выполнена под научным руководством к.э.н., доцента Морозовой Т. В., кафедра бухгалтерского учета и налогообложения, РЭУ им. Г. В. Плеханова
\end{abstract}

Ключевые слова: языки программирования, электронные форматы обмена данными, цифровая экономика, формат XML

Введение. В условиях цифровой экономики повышается важность скорости передачи, обработки информационных данных. Одним из принципиальных критериев является критерий качества обмена деловыми данными. В бизнес-среде обмен деловыми данными с каждым годом совершенствуется, сокращая время на отправку, принятие и обработку информации. Обмен электронной информацией осуществляется как в пределах корпоративного документооборота, так и между контрагентами, равно как и между контролирующими органами и подотчетным бизнесом. Процессы передачи данных базируются на разных платформах, в основе которых лежит программное обеспечение. Единственно возможным инструментом создания компьютерных программ являются языки программирования. Процесс выбора языка программирования обусловлен поставленной задачей и множеством факторов, среди которых ключевым является предметная область применения.

Основная часть. Существует множество языков программирования, каждый из них обладает своей спецификой в конкретной области и имеет свои преимущества и особенности. В научной и учебной литературе языки программирования, прежде всего, определяются как система $[1,2]$. Например, С. А. Орлов отмечает, что «язык программирования - это система обозначений, необходимая для описания алгоритмов, а также структур данных» [3]. Похожее определение дается О. Л. Голицыной. «Язык программирования - это система обозначений, необходимая для описания программ, а также алгоритмов для ЭВМ». Исходя из этого, главной задачей языков программирования является написание компьютерных программ, которые применяются для передачи компьютеру инструкций не только по выполнению того или иного вычислительного процесса, но и организации управления отдельными устройствами.

Развитие языков программирования во многом зависит от эволюции компьютерной техники, а источником лоббирования - необходимость в оперативном управлении бизнес-процессами. В Таблице 1 представлена эволюция языков программирования, которые условно можно подразделить на 5 поколений. 
Таблица 1. Эволюция языков программирования*

\begin{tabular}{|c|c|c|}
\hline Поколения & Языки программирования & Особенности \\
\hline Первое & Машинные & $\begin{array}{l}\text { - сложность в освоении; } \\
\text { - ориентированы на использование в конкретной электрон- } \\
\text { ной вычислительной машине; }\end{array}$ \\
\hline Второе & Ассамблеры & $\begin{array}{l}\text { - простота в использовании; } \\
\text { - машинно-зависимы; }\end{array}$ \\
\hline Третье & $\begin{array}{l}\text { Языки высокого уров- } \\
\text { ня (Бейсик, Кобол, Си и } \\
\text { Паскаль) }\end{array}$ & $\begin{array}{l}\text { - человеко-ориентированные; } \\
\text { - простота в освоении; } \\
\text { - мобильные; }\end{array}$ \\
\hline Четвертое & Непроцедурные & - ориентированы на профессионального пользователя; \\
\hline Пятое & $\begin{array}{l}\text { Языки искусственного интел- } \\
\text { лекта, экспертных систем и } \\
\text { баз знаний (Пролог, Си++) }\end{array}$ & $\begin{array}{l}\text { - ориентированы на повышении интеллектуального уров- } \\
\text { ня электронной вычислительной машины и интерфейса с } \\
\text { языками }\end{array}$ \\
\hline
\end{tabular}

*Составлена автором по данным [5]

Комментируя данные таблицы 1 , можно отметить, считается, что зарождение языков программирования произошло в начале 1920-х годов и были они малофункциональными. По сути, они были ориентированы только на численные расчеты и прикладные задачи. Как отмечается некоторыми авторами, программы того времени были оптимизированы под аппаратную архитектуру конкретного компьютера, для которого, собственно, и предназначались [4].

Таким образом, развитие языков программирования напрямую связаны с развитием электронных средств связи, совершенствованием технических и качественных параметров оборудования. В зависимости от целей программирования, языки программирования можно классифицировать по функциональному признаку, или парадигме программирования. В процедурных языках программирования дается описание необходимых к выполнению действий. Таким образом, предусмотрена чёткая последовательность команд, которые необходимо выполнить компьютеру. К этому классу можно отнести большинство языков программирования: FORTRAN, Pascal, Basic, язык С и другие [5, 6].

Следующая группа языков относится к непроцедурным языкам программирования. Например, объектно-ориентированные языки программирования. Этот стиль программирования характеризуется широкими графическими возможностями и средой программирования. В Таблице 2 представлены объектно-ориентированные языки программирования, такие как Java, XML.

Таблица 2. Объектно-ориентированные языки программирования

\begin{tabular}{|c|c|c|}
\hline Название & Характеристика & Цели \\
\hline Java & $\begin{array}{l}\text { - язык создан компанией Sun в начале 90-х годов на } \\
\text { основе С++; } \\
\text { - очень популярен в настоящее время; } \\
\text { - поддержка всевозможных мобильных устройств, } \\
\text { встраиваемых в бытовую технику }\end{array}$ & $\begin{array}{l}\text { - он призван упростить разработку } \\
\text { приложений С++ путем исключения из } \\
\text { него низкоуровневых возможностей }\end{array}$ \\
\hline XML & $\begin{array}{l}\text { - язык создан в 1996году; } \\
\text { - формат XBRL не является новым отдельным язы- } \\
\text { ком программирования - он основан на широко ис- } \\
\text { пользуемом на практике языке программирования и } \\
\text { представляет собой его «диалект» для целей форми- } \\
\text { рования отчетности в бизнесе. }\end{array}$ & $\begin{array}{l}\text { - используется во многих аспектах } \\
\text { веб-разработки, но основная его зада- } \\
\text { ча - облегчение хранения и передачи } \\
\text { данных. }\end{array}$ \\
\hline
\end{tabular}


Комментируя данные таблицы 2, можно отметить, что главным преимуществом объектно ориентированных языков является решение задач в удобной для пользователя форме, благодаря активному пользовательскому интерфейсу. Развитие финансовой системы в России сопровождается увеличением количества отчетности, передаваемой в цифровом формате. Если в начале 1990-х годов отчетности было настолько мало, что в небольшой организации ее мог сделать один человек и даже вручную, то сейчас этими вопросами занимаются большие, хорошо автоматизированные отделы. И без компьютеров данный процесс представить невозможно [7, 8].

Наибольшая нагрузка по компонентам финансовой, статистической и надзорной отчетности ложится на кредитные организации. При этом ЦБ РФ обладает расширенными полномочиями, в надзорную сферу которого попадают финансовые, нефинансовые и страховые компании. Унифицированные форматы электронных сообщений для сбора отчетных данных на основе спецификации XML, предназначены для представления кредитными организациями, головными кредитными организациями банковских групп и субъектами национальной платежной системы в Банк России.

Можно отметить, что на современном этапе в процессе обмена деловой информацией ключевым форматом стандартизации электронных форматов является XML. На основе этого языка разработано множество модификаций, которые в той или иной степени применяются на практике. Одной из модификаций XML является расширяемый язык разметки XBRL $[9,10]$. В текущих бизнес-процессах XBRL рассматривается как формат предоставления финансовой отчетности, а также других видов стандартизированных отчетов контролирующим органам.

Заключение. По результатам проведенного исследования можно сделать вывод, что в условиях цифровой экономики повышается важность скорости передачи, обработки информационных данных. Процессы передачи данных базируются на разных платформах, в основе которых лежит программное обеспечение. Единственно возможным инструментом создания компьютерных программ являются языки программирования. Развитие языков программирования напрямую связано с развитием электронных средств связи, совершенствованием технических и качественных параметров оборудования. Стандартизация отчетной информации, как одна из задач обмена деловой информации, привела к созданию надстройки языка XML. Так язык разметки - XBRL, являющийся модификацией XML, активно применяется при передаче в электронном формате стандартизированных отчетов в контролирующие органы. По нашему мнению, применение формата XBRL не является однозначно приоритетным для бизнес-сферы, хотя имеет явные преимущества, относительно более ранних модификаций.

\section{Список использованных источников}

1. Голицына О. Л., Попов И. И. Основы алгоритмизации и программирования. Форум. // Инфра-М, 2015.432 с.

2. Морозова Т.В., Сафонова Э.Г., Калачева О.Н. Оценка влияния на таксономию МСФО-отчетности формата XBRL // Азимут научных исследований: экономика и управление. 2018. T.7. №2 (23). С. 273-241.

3. Одегов Ю.Г., Кулапов М.Н., Котова Л.Р., Сидорова В.Н., Бабынина Л.С., Балаханова Д.К., Ламскова О.М., Макушина Л.В. Организация самостоятельной работы студентов Санкт-Петербург, 2009.

4. Чайковская Л.А., Галайда А.М. Проблемы гармонизации бухгалтерского и налогового учета основных средств// Экономика и управление: проблемы, решения. 2017. Т. 2. № 8. С. 36-44.

5. Турищева Т.Б. Внутренний контроль и аудит. Теория и практика применения в финансово-хозяйственной деятельности организации: монография/Турищева Т.Б.-М.: ИД «Экономическая газета», ИТКОР, 2012.-134 с.

6. Юхимов Я.И., Юхимова Я.Я. Государственная поддержка - важнейшее условие сохранения потенциала горнорудной промышленности России в слоувиях мирового кризиса // Горный журнал. 2010. № 4. С. 37-39.

7. Bykanova O.A., Akhmadeev R.G., Kosov M.E., Ponkratov V.V., Osipov V.S., Ragulina Yu.V. Assessment of the economic potential of sovereign wealth funds//Journal of Applied Economic Sciences. 2017. T. 12. № 1 (47). C. 70-84.

8. Орлов С. А. Теория и практика языков программирования. Стандарт 3-го поколения. // СПб.: Питер. 2016. $688 \mathrm{c}$.

9. Мастеров А.И. Управленческий анализ смешанных затрат в условиях многономенклатурной реализации // Актуальные проблемы социально-экономического развития России. - 2012. - №2. - С. 21-24.

10. Пяткин В. В., Колчин А. И. Тенденции в развитии языков программирования - от машинного кода к JVM и CLR. // Вестник современных исследований. 2018. №7.2.9 (22). С. 200-203 


\author{
Ataullina Ruzaliya Rinatovna \\ Student of Master Degree \\ Plekhanov Russian University of Economics \\ Russian Federation, 117997, Moscow, Stremyanny lane, 36 \\ E-mail: ruzaliaa04@gmail.com
}

\title{
DEVELOPMENT OF LANGUAGES OF PROGRAMMING AND ELECTRONIC FORMATS OF EXCHANGE OF BUSINESS DATA IN BUSINESS - MEDIUM
}

Summary. The article conducted a study of electronic formats for exchanging business data in a business environment. Particular attention is paid to the terminological understanding of «programming languages», their development and classification. The classification of programming languages can be detailed according to a functional feature or programming paradigm. According to the results of the research, data from the business environment is used. The article is executed under the scientific guidance of Morozova T. V. candidate of economical science, associate professor of the chair «Accounting and Taxation» of Plekhanov Russian University of Economics

Keywords: programming languages, electronic data interchange formats, digital economy, XML format 